\title{
Too big to go out: gastric endoscopic submucosal dissection of giant lipoma complicated by intestinal obstruction
}

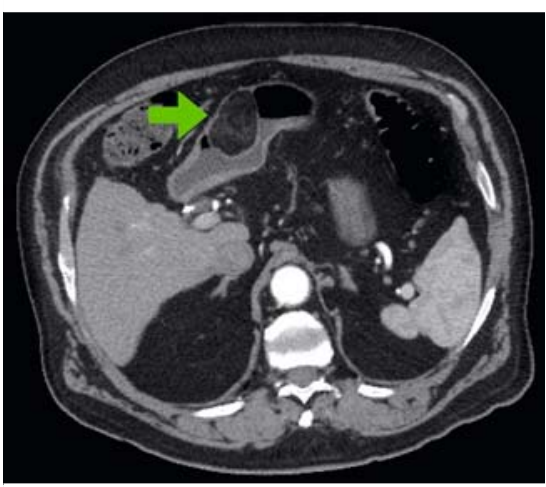

- Fig. 1 Contrast-enhanced computed tomography scan showed a sub-epithelial mass located in the anterior wall of the gastric antrum (green arrow).

Gastrointestinal sub-epithelial tumors are frequently diagnosed during endoscopy but they are usually small and do not require any treatment owing to benign behavior [1-2]. Sometimes these lesions can cause symptoms and their resection is needed [3].

Here we report the case of a 78-year-old man who underwent gastroscopy for intermittent melena and postprandial abdominal discomfort.

Esophagogastroduodenoscopy (EGD) revealed a huge sub-epithelial lesion, covered by ulcerated mucosa, located in the antrum. After needle knife biopsy, histopathology was consistent with lipoma.

Despite medical therapy, the patient referred with melena once again, hence endoscopic submucosal dissection (ESD) was planned.

The lesion was $8 \times 6 \mathrm{~cm}$ ( $>$ Fig. 1 ), arising from the submucosal layer. The ESD took 100 minutes and was performed with the pocket creation technique using the DualKnife J $(1.5 \mathrm{~mm})$ and ITknife nano (Olympus. Tokyo, Japan) [4].

For a small intercurrent perforation, a traumatic type over-the-scope clip

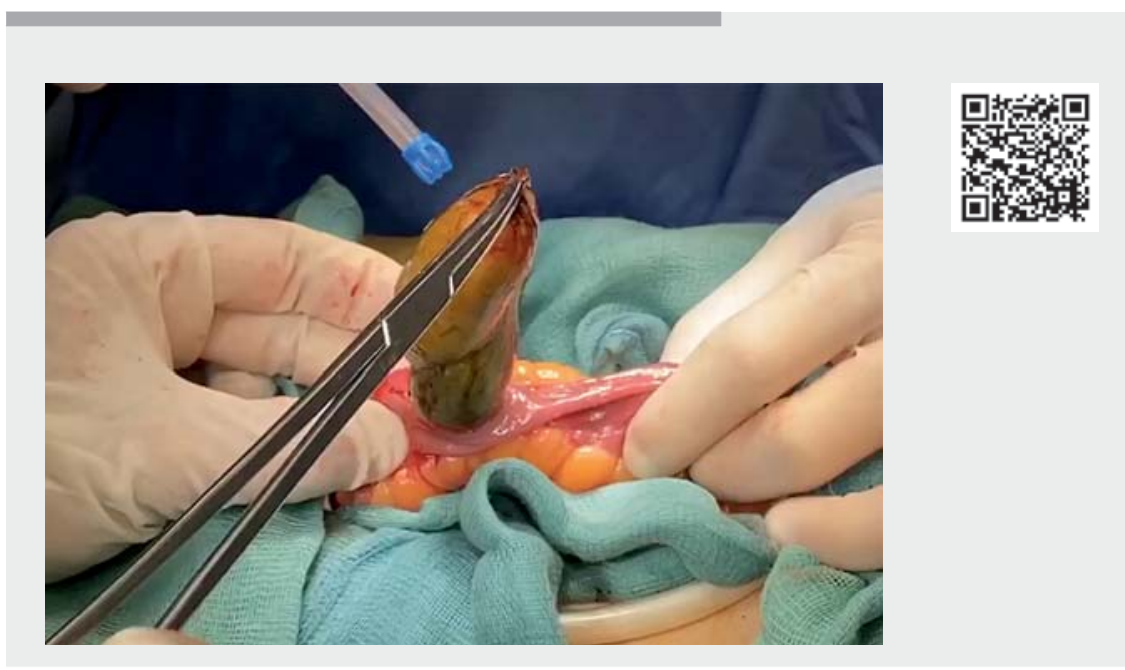

Video 1 Endoscopic submucosal dissection of a gastric sub-epithelial mass complicated by intestinal obstruction and treated with surgical enterotomy.

(OTSC) (Ovesco Endoscopy, Tübingen, Germany) was successfully released.

After en bloc resection, the lesion was not pulled out because of its huge dimension in contrast with the smaller diameter of the upper and lower esophageal sphincter. Based on our previous experience, we decided on degradation and digestion in the stomach rather than passage through the pylorus, and thus the resected mass was left in the gastric cavity [5]. The day after, the patient developed obstructive symptoms like blotting and bilioenteric vomiting. A computed tomography (CT) scan revealed a jejunoileal occlusion caused by an intraluminal fat mass, and therefore the patient underwent an urgent laparoscopic enterotomy and the giant resected lipoma was finally extracted ( $\downarrow$ Video 1 ).

Lipomas are composed of hard and cohesive fat aggregates. Their digestion may be extremely slow and sometimes incomplete, especially after ESD when high dosages of proton pump inhibitors (PPI) are administered.
In this context, after dissection, extra time for chopping and extraction should be considered to avoid this rare but serious complication.

Endoscopy_UCTN_Code_CPL_1AH_2AZ

Competing interests

The authors declare that they have no conflict of interest.

The authors

Giuseppe Grande ${ }^{1}$, Flavia Pigò ${ }^{1}$, Angelo Caruso ${ }^{1}$, Salvatore Russo ${ }^{1}$, Marinella Lupo ${ }^{1}$, Micaela Piccoli ${ }^{2}$, Rita Conigliaro ${ }^{1}$

1 Gastroenterology and Digestive Endoscopy Unit, Azienda Ospedaliero-Universitaria di Modena, Baggiovara, Modena, Italy

2 Division of General, Emergency Surgery and New technologies Unit, Azienda Ospedaliero-Universitaria di Modena, Baggiovara, Modena, Italy 
Corresponding author

\section{Giuseppe Grande, MD}

Gastroenterology and Digestive Endoscopy Unit, Azienda Ospedaliero-Universitaria di Modena, Via Giardini 1355, Baggiovara, Modena, Italy

grande.giuseppe@aou.mo.it

\section{References}

[1] Cappell MS, Stevens CE, Amin M. Systematic review of giant gastric lipomas reported since 1980 and report of two new cases in a review of 117110 esophagogastroduodenoscopies. World J Gastroenterol 2017; 23: 5619-5633

[2] Sullivan IW, Hota P, Dass C. Gastric lipomas: a case series and review of a rare tumor. BJR Case Rep 2019; 5: 20180109

[3] Sabbah M, Nakhli A, Helal I et al. Gastrointestinal bleeding as an initial manifestation of gastric lipoma: case report and review of the literature. Clin Case Rep 2020; 8: 19881992

[4] Lv X-H, Wang CH, Xie Y. Efficacy and safety of submucosal tunneling endoscopic resection for upper gastrointestinal submucosal tumors: a systematic review and meta-analysis. Surg Endosc 2017; 3: 49-63

[5] Manno M, Soriani P, Mirante VG et al. Endoscopic dissection of a symptomatic giant gastric leiomyoma arising from the muscularis propria. Endoscopy 2017; 49: E141E142

\section{Bibliography}

Endoscopy 2021; 53: E474-E475

DOI 10.1055/a-1346-8122

ISSN 0013-726X

published online 4.2.2021

(C) 2021. Thieme. All rights reserved.

Georg Thieme Verlag KG, Rüdigerstraße 14,

70469 Stuttgart, Germany
ENDOSCOPY E-VIDEOS

https:/|eref.thieme.de/e-videos

口回 Endoscopy E-Videos is a free Fection, reporting 田: on interesting cases and new techniques in gastroenterological endoscopy. All papers include a high quality video and all contributions are freely accessible online.

This section has its own submission website at https://mc.manuscriptcentral.com/e-videos 